Andrew J. Ridley · James Colley

David Wynford-Thomas · Christopher J. Jones

\title{
Characterisation of novel mutations in Cockayne syndrome type A and xeroderma pigmentosum group $C$ subjects
}

Received: 11 November 2004/ Accepted: 19 December 2004 / Published online: 3 March 2005

(C) The Japan Society of Human Genetics and Springer-Verlag 2005

\begin{abstract}
We report that a subject with Cockayne syndrome type A (CS3BE) was a compound heterozygote for mutations in CKN1, the gene encoding the CSA protein (MIM 216400). CS3BE displayed a novel missense mutation (A160V) and a previously described nonsense mutation (E13X). Although residing between the second and third WD-40 repeats characteristic of the CSA protein, A160 is completely conserved in all species that possess a $C K N 1$ homologue. We also describe a mutation in a previously uncharacterised xeroderma pigmentosum group $\mathrm{C}$ subject (XP8CA) in the XPC gene (MIM 278720). XP8CA was homozygous for a 2 bp TG deletion in codon 547 resulting in premature termination at codon 572. Immunoblotting of XP8CA extracts confirmed the absence of full-length XPC protein that was present in unaffected cell lines.
\end{abstract}

Keywords Hyperphotosensitivity · Skin neoplasia · Progeria $\cdot$ Nucleotide excision repair $\cdot$ Xeroderma pigmentosum $\cdot$ Cockayne syndrome

\section{Introduction}

The human genome is under perpetual attack from a range of endogenous and exogenous genotoxic agents (Lindahl 1993). Genome stability is maintained by a set of integrated DNA repair pathways, which comprise at least 130 gene products (Wood et al. 2001). Of these

\footnotetext{
A. J. Ridley · D. Wynford-Thomas · C. J. Jones $(\square)$

Department of Pathology, School of Medicine, Cardiff University, Heath Park, Cardiff, CF14 4XN, UK

E-mail: Jonescj@cf.ac.uk

Tel.: + 44-2920-744849

Fax: + 44-2920-744276

J. Colley

Wales Gene Park, Institute of Medical Genetics, Cardiff University, Heath Park, Cardiff,

CF14 4XN, UK
}

pathways the most versatile is nucleotide excision repair (NER), a highly conserved mechanism that requires at least 30 polypeptides (Aboussekhra et al. 1995). Lesions removed by NER include UV-induced photoproducts. Loss of function of some NER genes is incompatible with life whilst defects in a subset of proteins can result in developmental abnormalities or cancer.

Xeroderma pigmentosum (XP) is characterised by hyperphotosensitivity to the UV constituent of sunlight. The hallmark of XP is a predisposition to skin neoplasia, with a $>1,000$-fold incidence of UV-induced squamous cell carcinoma and malignant melanoma. Classical XP is caused by mutations in one of seven genes $X P A-X P G$. Cockayne syndrome (CS) patients do not have a predisposition to UV-induced skin neoplasia but exhibit a battery of clinical manifestations, such as segmental progeria, cachetic dwarfism, deafness, retinal degeneration, neurological dysfunction and skeletal-associated abnormalities including osteoporosis and a bird-like face. Death occurs at a mean age of 12 years. Mutations in the $C K N 1$ (CSA) and $C S B$ genes are responsible for CS.

Whilst CS and XP cells have defective NER, the striking differences between the syndromes are explained by the fact that the NER mechanism is divided into two distinct sub-pathways. Global genome repair (GGR) facilitates the removal of lesions from the non-transcribed strand and transcriptionally silent regions of the genome. Transcription-coupled repair (TCR) preferentially removes lesions from the transcribed strand of active genes. In GGR, the recruitment of the $106 \mathrm{kDa}$ XPC protein complexed with the $43 \mathrm{kDa}$ hHR23B protein allows interaction with damaged DNA, facilitating the recognition of UV-induced lesions (Sugasawa et al. 1998). Conversely, the arrest of an elongating RNA polymerase II at a lesion on the transcribed strand of an active gene elicits the recruitment of TCR-specific proteins, including CSA. The $44 \mathrm{kDa}$ CSA protein is encoded by the CKN1 gene and contains multiple WD40 repeats (Henning et al. 1995). The two NER subpathways converge at the point where the presence of a 
lesion is confirmed. Excision, re-synthesis and ligation follow using a common mechanism.

Both $X P C$ and $C K N 1$ genes were cloned as a result of screening cDNA libraries for genes that corrected the UV sensitivity of XP-C and CS-A cell lines. The mutations present in the original CS-A line used for library screening (CS3BE) have not previously been identified (Henning et al. 1995) although it was reported that the cell line appeared to produce no CSA protein (van Gool et al. 1997). Here we report a novel mutation in the CKN1 gene of this patient and the defect in a previously uncharacterised XP-C cell line, XP8CA.

\section{Materials and methods}

Cell lines and culture conditions

MRC-5 foetal lung fibroblasts were purchased from ECACC and were grown in monolayers in Eagle's minimum essential medium with Earle's salts (EMEM, Invitrogen), supplemented with $10 \%$ foetal calf serum (FCS; Imperial Laboratories, London), 1× MEM nonessential amino acids (NEAA) without $\mathrm{L}$-glutamine. XPC (GM02996, XP8CA), CS-A (GM01856, CS3BE) and XP-A (GM05509, XP12BE) diploid primary human fibroblasts were purchased from Coriell and grown as monolayers in EMEM with Earle's salts with $10 \%$ FCS, $2 \times$ MEM NEAA without L-glutamine, $2 \times$ essential amino acids MEM, $2 \mathrm{mM}$ L-glutamine, $2 \times$ MEM vitamins. All media were supplemented with penicillin $(10,000 \mathrm{U} / \mathrm{ml})$ and streptomycin $(10 \mu \mathrm{g} / \mathrm{ml})$ and cells grown at $37^{\circ} \mathrm{C}$ in a humidified incubator with $5 \% \mathrm{CO}_{2}$. G418 $(400 \mu \mathrm{g} / \mathrm{ml})$ was used for cells undergoing drug selection.

Telomerase immortalisation of cell lines

The catalytic sub-unit of telomerase, human telomerase reverse transcriptase (hTERT), was transduced into MRC-5, XP8CA, CS3BE and XP12BE primary cells using an amphotropic retroviral vector, $\mathrm{pBABE}$ neo hTERT, using protocols previously described (Wyllie et al. 2000).

PCR amplification of $X P C$ and $C K N 1$ gene fragments from isolated genomic DNA

Genomic DNA was isolated and purified using RNase A treatment and proteinase $\mathrm{K}$ digestion, followed by a standard phenol/chloroform extraction. PCR primer sets (Table 1), used to amplify $X P C$ and $C K N 1$ coding regions and intron-exon boundaries from XP8CA and CS3BE genomic DNA were devised using NCBI sequences NT_022517.17 and NT_006713.14, respectively. Thermocycling was performed on an MJ Tetrad.
Amplification conditions were $95^{\circ} \mathrm{C}$ for $12 \mathrm{~min}$, followed by 33-35 cycles of $30 \mathrm{~s}$ each at $94^{\circ} \mathrm{C}$, the primer specific annealing temperature, and $72^{\circ} \mathrm{C}$, ending with a final 10 -min extension step at $72^{\circ} \mathrm{C}$.

Screening $X P C$ and $C K N 1$ for genomic DNA variants

PCR products were purified using an exonuclease I, shrimp alkaline phosphatase PCR purification protocol (Amersham). PCR amplification products were prepared for sequencing using the BigDye Terminator version 3.1 Cycle Sequencing Reaction Ready Kit (Applied Biosystems) and excess dye terminators removed using Montage $\mathrm{Seq}_{96}$ Sequence Reaction Cleanup Kits (Millipore). Sequence analysis of $X P C$ and $C K N 1$ was performed on an ABI PRISM 3100 Genetic Analyser.

\section{Analysis of CS3BE CKN1 mRNA}

Total RNA was isolated using TRIzol and reverse transcribed with SuperScript II (both Invitrogen). Amplification of $C K N 1$ cDNA was performed using Taq polymerase (Promega) using the primers $5^{\prime}$-GGT TTT TGT CCG CAC GCC AA-3' (forward) and 5'-GTG GAG ACC AGG AAA CTG CT-3' (reverse). PCR products were ligated into the TA cloning vector $\mathrm{pCR} 2.1$ and transformed into INV $\alpha \mathrm{F}^{\prime}$ Escherichia coli One Shot cells (Invitrogen). Individual colonies were expanded and sequenced (as above) in both directions using M13 forward and reverse primers.

\section{Immunoblotting}

Whole-cell extracts were prepared, as previously described (Evans et al. 2003). Proteins were separated on $8 \%$ (XPC) and 12\% (CSA) SDS polyacrylamide gels, transferred to Immobilon polyvinylidene difluoride (PVDF) membranes (Millipore) and exposed to either an anti-XPC mouse monoclonal antibody (ab6264; Abcam) or anti-CSA goat polyclonal antibody (W-16: sc-10997; Santa Cruz). Blots were visualised using an appropriate HRP-coupled secondary antibody and an ECL system using Hyperfilm (Amersham). Equal protein loading was confirmed by staining the PVDF membrane with India ink.

\section{Results and discussion}

Primary human diploid fibroblasts have a limited lifespan in culture due to telomere-dependent replicative senescence. In order to provide sufficient material for biochemical analysis, we infected MRC-5, CS3BE, $\mathrm{XP} 8 \mathrm{CA}$ and XP12BE with a retrovirus expressing the catalytic subunit of telomerase (hTERT) and isolated subclones. The extended lifespan of these lines con- 
Table 1 Forward and reverse primer sets for $C K N 1$ and $X P C$ amplification from genomic DNA

\begin{tabular}{|c|c|c|c|}
\hline Exon & Forward & Reverse & Product size $(\mathrm{bp})$ \\
\hline \multicolumn{4}{|l|}{$C K N 1$} \\
\hline 1 & 5'-GAC TCT GCT GTT CCA GTC C & 5'-CAA AGC TTA CAG TCA TTG GTC C & 220 \\
\hline 2 & 5'-TAC GTT AGG ATG TGT GGT AG & 5'-ATG CCA GAT TCA AAA ATG CTA C & 500 \\
\hline 3 & 5'-TGA AGT CTG TGT TAT TGA GG & 5'-CAG TCA AGT GAA TGG GTC AA & 363 \\
\hline 4 & 5'-ATG TGA TCT CGG TTT GGC & 5'-GGA TTA AAT TCT CCT TTA TCC TAC & 302 \\
\hline 5 & 5'-TGT TTA AGT TGA ATT GCT AAC AGT C & 5'-TTG TGA TAT TCC TCT GGG & 316 \\
\hline 6 & 5'-TTC TGC ATG GAT ACA GTG AAA ATG & 5'-TGA GTC TCA ACA ACC AGC AC & 302 \\
\hline 7 & 5'-CAC TTT CTT CAG AAT CAG GC & 5'-GGA AGA TTT CTT TTG GTG ACA & 367 \\
\hline 8 & 5'-TAA CGA GAC CTC TGT GTG CCA & 5'-GAA AGT GAT ATA CGA TGA ATG CC & 342 \\
\hline 9 & 5'-GTA ACT CAA GTA GTT GTC CT & 5'-ATC AAG TGT ATG TCA CAG ATC C & 295 \\
\hline 10 & 5'-AGT ATT TCT CCT AGG CTT TGT TGT G & 5'-ACA TAT AAC TGG TCT GGC AAG C & 334 \\
\hline 11 & 5'-ATT GGC CTA GTT TCT TTA GGG AG & 5'TAA GCT TTA GAA GTC ACT GTA CC & 299 \\
\hline 12 & 5'-TTT TCT TCC AAA ATA ATG TAA TTG CT & 5'-CTG TAT GGT CTA TTC CTG AC & 235 \\
\hline \multicolumn{4}{|c|}{ 211 } \\
\hline 1 & 5'-TGA CTA GGC CTC CAA CGA AG & 5'-TAC GCA GGA GCT TGG ATC G & 453 \\
\hline 2 & 5'-ATA AGC TGC ACT GCC TCC AC & 5'-GAT CCA ATC TTC CAT GGA CC & 371 \\
\hline 3 & 5'-GCT TGA ATG GAA CAC TAG G & 5'-TAG TGA TCT GAC TCC AAA CAG & 257 \\
\hline 4 & 5'-TGA TTC TGT TCA GTA CAG TAG C & 5'-CAA AGT CCT CCT AAG CAG C & 308 \\
\hline 5 & 5'-GAG GAG AAG GAA TTG CCT G & 5'-AGC ACA AGC TCT TTG CAC C & 224 \\
\hline 6 & 5'-CAT GTC TTG ACT TTG GCA GC & 5'-CTG TGG AAG TGA CCT GAA CC & 325 \\
\hline 7 & 5'-CTT GGC TGG AAA TGA AAA TTC C & 5'-GCA CAT GGC TGC CAT TAT C & 257 \\
\hline 8 & 5'-TTC TTA GGA TAA CTA TGT TCT TCC & 5'-ACT CCG TGA ATA CCA GCT C & 232 \\
\hline 9.1 & 5'-CTC TAG CTG GTG ACT TAA CC & 5'-CTT GAA GAG CTT GAG GAT GC & 453 \\
\hline 9.2 & 5'-GCT CTG ATT TTG AGC TCT CC & 5'-CCT GAC TGT GTC TTG GAG C & 588 \\
\hline 10 & 5'-GTC TAA GGA TCA TCT CCC TC & 5'TGC TGT CCA GTC AGA TGA GC & 344 \\
\hline 11 & 5'-ACG TTC AAG GCT GTT TGC C & 5'-GCT CAT CAT CAC TTC TCT GC & 344 \\
\hline $12 / 13$ & 5'-TGA GGA ACT GGA TGC CTT TG & 5'-TGA AAA TTG GAG CCA CCA GG & 558 \\
\hline 14 & 5'-CAC TGT CTT CCA CAA ACT GG & 5'-TGT ATT CAG TGC TCG CTC C & 333 \\
\hline 15 & 5'-ACT TGG TGT GAA GGA GAG GC & 5'-CCT TTC TGA GCT GCA TCT CC & 291 \\
\hline 16 & 5'-GAA CTT GCT GCC TCT TCA TGG & 5'-TGC CTT CTC AGC AGA GAA GC & 416 \\
\hline
\end{tabular}

firmed that hTERT expression had immortalised the cultures (not shown). The repair-defective cell lines also retained their UV sensitivity (not shown). Genomic DNA from these cell lines was isolated and the 12 exons of $C K N 1$ and 16 exons of $X P C$ were amplified by PCR (Table 1). PCR products were sequenced and base changes identified by comparing to consensus cDNA sequences (NM_000082 [CKN1]; NM_004628 [XPC]).

The original assignment of patient XP8CA to XP complementation group $\mathrm{C}$ was made of the basis of cell fusion studies. In XP8CA, a homozygous 2 bp TG deletion, was identified in codon 547 at position 1639 . This would result in a frame shift and a predicted protein product of $63.4 \mathrm{kDa}$. Two further homozygous changes were identified: $2061 \mathrm{~A}>\mathrm{G} \quad(\mathrm{R} 687 \mathrm{R})$ and 2815A $>$ C (K939Q). Immunoblotting using an XPCspecific antibody confirmed the absence of full-length protein in XP8CA. XPC protein was present in CS-A and XP-A and normal MRC-5 cell extracts (Fig. 1). $\mathrm{XPC}$ protein levels were slightly reduced in the CS-A cell extract. XPC is an inducible protein (Adimoolam and Ford 2002), and the lower expression in CS3BE cells reflects a different steady state level compared to other cell lines. The presence of a further mutation at K939 is likely to have no effect because firstly, translation terminates prior to the mutation, and secondly, K939 is adjacent to the final amino acid of the normal protein. The majority of previously reported $X P C$ mutations result in truncated proteins (Chavanne et al. 2000), and an identical mutation to that in XP8CA has been reported in the patient XP4PA (Li et al. 1993). The relationship between patients XP8CA and XP4PA is unknown although they were originally identified in different laboratories.

CS3BE, assigned to CS complementation type A, was a compound heterozygote for $C K N 1$ mutations $37 \mathrm{G}>\mathrm{T}$ (E13X) and 479C $>$ T (A160V). Immunoblot analysis of CS3BE and MRC-5 cell extracts using an anti-CSA antibody detected a non-specific cross-reacting band (Fig. 1). However, a band corresponding to CSA was present in MRC-5 and absent in CS3BE, confirming the earlier report that the protein was not expressed in the cell line (van Gool et al. 1997). It was confirmed that the mutations were on separate alleles by reverse transcription of CS3BE total RNA followed by PCR. Products were sub-cloned and sequenced, and in clones where $37 \mathrm{G}>\mathrm{T}$ was present, the $479 \mathrm{C}>\mathrm{T}$ mutation was absent. No clones were recovered containing the $479 \mathrm{C}>\mathrm{T}$ mutation although cDNA containing the wild-type $37 \mathrm{G}$ appeared to have spliced out the exon containing $479 \mathrm{C}>\mathrm{T}$. The instability of mRNA from the second allele is likely to explain the lack of CSA protein in the cells.

To date, the availability of $C K N 1$ mutation data is limited because although mutations in the $C K N 1$ gene account for approximately $20 \%$ of CS (Stefanini et al. 1996), only eight have been characterised (Cao et al. 2004; Ren et al. 2003). Here we report a third missense 


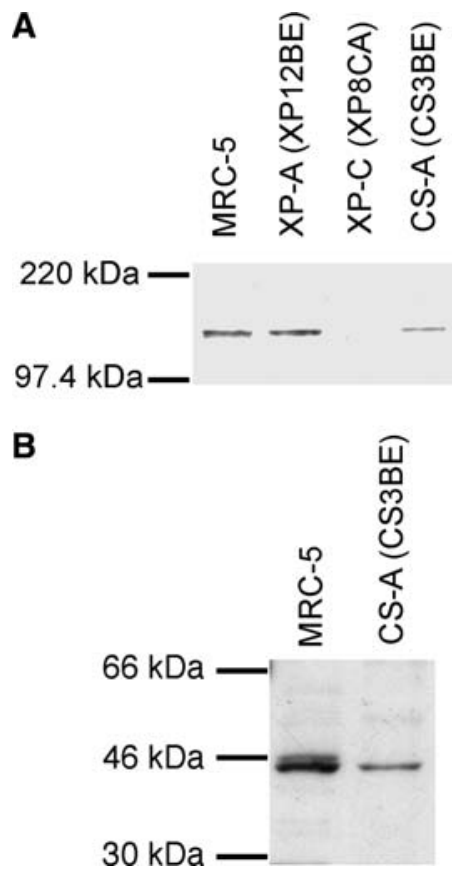

Fig. 1 Loss of expression of XPC and CSA proteins in mutant cell lines. a Protein extracts $(20 \mu \mathrm{g})$ from a normal (MRC-5) and DNA repair-defective XP-A, XP-C and CS-A cell lines were separated on SDS-PAGE gels, transferred and membranes probed with an antiXPC antibody. A band of approximately $125 \mathrm{kDa}$ corresponding to XPC protein was absent in XP8CA consistent with the predicted truncated product. b Protein extracts $(20 \mu \mathrm{g})$ from MRC-5 and CS3BE (CS-A) were separated as above and transferred protein probed with an anti-CSA antibody. CS3BE cell extracts showed no expression of a protein of approximately $44 \mathrm{kDa}$ (upper band) that was present in MRC-5 extracts

mutation in CKN1. The Utah Genome Center SNP database (http://www.genome.utah.edu/genesnps) and a previous study (Cao et al. 2004) indicate that this is not an SNP. The availability of genomes from other species has shown that the CSA protein is highly conserved (data not shown; http://www.ensembl.org). The two previously reported missense mutations (Q106P and A205P) lie in the WD-40 regions. The A160V mutation reported here lies between the second and third WD-40 repeats. If undetectably low levels of full-length protein are expressed in CS3BE, this is likely to be inactive as the sites of all three missense mutations (Q106, A205 and A160) are highly conserved in mammalian, chicken and puffer fish CSA protein homologues. Unlike Q106 and A205, A160 is retained in Schizosaccharomyces pombe and Arabidopsis thaliana. The role of CSA in DNA repair is still poorly understood, and the existence of this highly conserved region suggests a possible avenue for elucidating the function of this protein.

Acknowledgements We thank the Biotechnology and Biological Sciences Research Council and Wales Gene Park for funding and Rebecca Capper for technical support.

\section{References}

Aboussekhra A, Biggerstaff M, Shivji MK, Vilpo JA, Moncollin V, Podust VN, Protic M, Hubscher U, Egly JM, Wood RD (1995) Mammalian DNA nucleotide excision repair reconstituted with purified protein components. Cell 80:859-868

Adimoolam S, Ford JM (2002) p53 and DNA damage-inducible expression of the xeroderma pigmentosum group $\mathrm{C}$ gene. Proc Natl Acad Sci USA 99:12985-12990

Cao H, Williams C, Carter M, Hegele RA (2004) CKN1 (MIM 216400): mutations in Cockayne syndrome type A and a new common polymorphism. J Hum Genet 49:61-63

Chavanne F, Broughton BC, Pietra D, Nardo T, Browitt A, Lehmann AR, Stefanini M (2000) Mutations in the XPC gene in families with xeroderma pigmentosum and consequences at the cell, protein, and transcript levels. Cancer Res 60:1974-1982

Evans RJ, Wyllie FS, Wynford-Thomas D, Kipling D, Jones CJ (2003) A P53-dependent, telomere-independent proliferative life span barrier in human astrocytes consistent with the molecular genetics of glioma development. Cancer Res 63:4854-4861

van Gool AJ, Citterio E, Rademakers S, van Os R, Vermeulen W, Constantinou A, Egly JM, Bootsma D, Hoeijmakers JH (1997) The Cockayne syndrome B protein, involved in transcriptioncoupled DNA repair, resides in an RNA polymerase II-containing complex. EMBO J 16:5955-5965

Henning KA, Li L, Iyer N, McDaniel LD, Reagan MS, Legerski R, Schultz RA, Stefanini M, Lehmann AR, Mayne LV (1995) The Cockayne syndrome group A gene encodes a WD repeat protein that interacts with CSB protein and a subunit of RNA polymerase II TFIIH. Cell 82:555-564

Li L, Bales ES, Peterson CA, Legerski RJ (1993) Characterization of molecular defects in xeroderma pigmentosum group C. Nat Genet 5:413-417

Lindahl T (1993) Instability and decay of the primary structure of DNA. Nature 362:709-715

Ren Y, Saijo M, Nakatsu Y, Nakai H, Yamaizumi M, Tanaka K (2003) Three novel mutations responsible for Cockayne syndrome group A. Genes Genet Syst 78:93-102

Stefanini M, Fawcett H, Botta E, Nardo T, Lehmann AR (1996) Genetic analysis of twenty-two patients with Cockayne syndrome. Hum Genet 97:418-423

Sugasawa K, Ng JM, Masutani C, Iwai S, van der Spek PJ, Eker AP, Hanaoka F, Bootsma D, Hoeijmakers JH (1998) Xeroderma pigmentosum group $\mathrm{C}$ protein complex is the initiator of global genome nucleotide excision repair. Mol Cell 2:223-232

Wood RD, Mitchell M, Sgouros J Lindahl T (2001) Human DNA repair genes. Science 291:1284-1289

Wyllie FS, Jones CJ, Skinner JW, Haughton MF, Wallis C, Wynford-Thomas D, Faragher RG, Kipling D (2000) Telomerase prevents the accelerated cell ageing of Werner syndrome fibroblasts. Nat Genet 24:16-17 